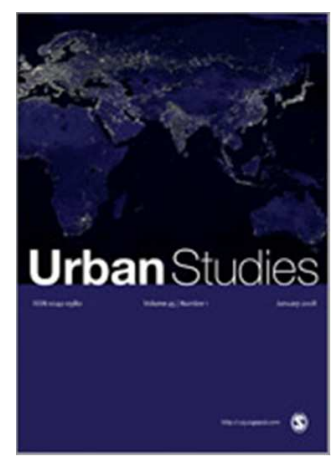

\title{
SEGREGATION AND THE EFFECTS OF ADOLESCENT RESIDENTIAL CONTEXT ON POVERTY RISKS AND EARLY INCOME CAREER: A STUDY OF THE SWEDISH 1980 COHORT
}

\begin{tabular}{|c|c|}
\hline Journal: & Urban Studies \\
\hline Manuscript ID & CUS-1041-15-12.R1 \\
\hline Manuscript Type: & Article \\
\hline $\begin{array}{r}<b>\text { Discipline: Please select a } \\
\text { keyword from the following list } \\
\text { that best describes the } \\
\text { discipline used in your paper.: }\end{array}$ & Geography \\
\hline $\begin{array}{r}\text { World Region: Please select } \\
\text { the region(s) that best reflect } \\
\text { the focus of your paper. } \\
\text { Names of individual countries, } \\
\text { cities \& economic groupings } \\
\text { should appear in the title } \\
\text { where appropriate.: }\end{array}$ & Western Europe, Europe \\
\hline $\begin{array}{l}\text { Major Topic: Please identify up } \\
\text { to two topics that best identify } \\
\text { the subject of your article.: }\end{array}$ & Neighbourhood, Methods \\
\hline $\begin{array}{r}\text { Please supply a further } 5 \\
\text { relevant keywords in the fields } \\
\text { below: }\end{array}$ & neighbourhood context, neighbourhood effect, poverty, income, Sweden \\
\hline
\end{tabular}




\begin{abstract}
:
Will the consequences of residential segregation, that is, spatial concentration of marginalized populations on the one hand, and spatial concentration of affluent populations on the other hand, generate a situation where individual life trajectories are influenced by where individuals grow up? Our aim is to analyze how poverty risks and early income career at adult age are influenced by different neighborhood contexts in early youth. We use Swedish longitudinal register data, and follow individuals born in 1980 until 2012. Residential context is measured in 1995 at age 15 by expanding a buffer around the residential locations of each individual and, by computing statistical aggregates of different sociodemographic variables for that population. The results show that poverty risks increase for individuals growing up in areas characterized by high numbers of social allowance recipients living nearby, whereas elite geographical context is favorable for both women's and men's future income.
\end{abstract}

Keywords: neighborhood context, neighborhood effects, poverty, income,

Acknowledgements: This research was supported by the Stockholm University Linnaeus Center on Social Policy and Family Dynamics in Europe, SPaDE, grant 349-2007-8701 of the Swedish Research Council. The Equipop software used for computing contextual variables based on individualized neighborhoods was developed by John Östh, Uppsala University. 


\section{INTRODUCTION}

Today, measures of spatial variation need not be restricted to using aggregates for fixed geographical subdivision. Instead, it is possible to compute multi-scalar measures of geographical context to measure context using both multiple socio-demographic indicators and multiple geographical scales. These advances have been important both for the analysis of segregation patterns (Clark, Anderson, Östh, \& Malmberg, 2015; Reardon et al., 2009) and for the development of composite measures of geographical context that can be used to assess neighborhood effects (E. K. Andersson \& Malmberg, 2015; Chaix, Merlo, Subramanian, Lynch, \& Chauvin, 2005; Holloway, Wright, \& Ellis, 2012; Östh, Malmberg, \& Andersson, 2014). In this paper, the questions about neighborhood characteristics and scale will be addressed using an explicitly multi-scalar approach. Our aim is to analyze how poverty risks and early income career at adult age are influenced by different neighborhood contexts in early youth.

Earlier research into neighborhood effects on predominantly education and class, has indicated the need for an approach including some kind of indicator for elite context (Barthon \& Monfroy, 2010). The importance of interaction with elite groups for the reproduction of advantaged social positions has been repeatedly stressed by scholars such as Bourdieu (e.g. E. K. Andersson \& Malmberg, 2015; Bourdieu, 1984). His analysis, as discussed by Toft (2015), clearly suggests that residing in affluent neighborhoods can help individuals to accumulate different forms of social capital that promote an elite career. Here the social mechanisms in play (Ainsworth, 2002; Friedrichs, 2015) are suggested to be tied to social capital, spatial capital and social support.

Another type of context often researched in neighborhood effects literature is the foreign-born context. The roots of the theory that neighborhoods dominated by foreignborn residents are not beneficial for individuals' future work and for earning a reasonable income, can be found in American research about African Americans (Wilson, 1987). However, the American literature in this field of research is not directly comparable with the European situation, see for instance Wacquant (2008). In the Swedish research tradition, foreign-born neighborhoods are often considered equivalent to suburbs, located in rather isolated positions away from the metropolitan centers, and built in the period 1964-1975.

Also debated in neighborhood effect research are the influences on young people's life trajectories of living in areas with high unemployment and poverty. This research has a long tradition in which high unemployment environments are considered negative for the opportunities of youth (Ludwig, 1999; Wilson, 1987). The reason why certain areas or rather larger urban districts are unsupportive of finding work is also referred to as the mismatch between workers and employers. The influence of poverty neighborhoods on adolescents is probably the main theme researched in the neighborhood effects 
literature, and it is probably needless to say such influence is considered negative for children's and adolescents' future life course trajectories (Brooks-Gunn \& Duncan, 1997; Brännström, 2004; Friedrichs, 1998; Galster, Marcotte, Mandell, Wolman, \& Augustine, 2007; Holloway \& Mulherin, 2004; Jencks \& Mayer, 1990; Massey, Gross, \& Shibuya, 1994; McCulloch, 2001; South \& Crowder, 1999).

Also, based on earlier research we can make assumptions about how housing can affect adolescents to take certain life trajectories. Single-family housing forming large areas with a middle-class population in the Swedish case will be a particular concern in our analysis. Earlier research has pointed to the will of policy makers to expect responsible, caring homeowners to stabilize neighborhoods because of the investments they make in their housing (Doling \& Ronald, 2010). In addition, competition in housing markets will result in only the middle-class and richer segments of the population being able to afford single-family housing and being able to enter the home owning sector with a mortgage. Usually, neighborhood effects from single-family housing areas have a positive influence on adolescents' future achievements (Andersson \& Malmberg, 2015) but the opposite is also possible (van Ham \& Manley, 2009).

In order to construct measures of residential context we have selected indicator variables that can capture the different types of neighborhood milieus that have been discussed in the neighborhood effect literature. For elite environments, the presence of top income earners and individuals with tertiary education has been identified as a relevant indicator. The migrant status of neighbors is a natural measure of foreign-born context. As indicators of poverty context, this paper will employ indicators of employment and social allowance recipiency in combination with single motherhood. Finally, single-family housing will be used as an indicator of middle-class neighborhoods.

To assess the influence of these indicator variables we will employ a novel approach to context measurement that is based on multi-scalar individualized neighborhoods. This approach acknowledges the fact that individuals are not only influenced by the social context of their immediate surroundings; they also interact with, and can be influenced by, community-based institutions that serve smaller or larger geographical areas. Moreover, local employment opportunities can influence the expectations that individuals have with respect to different career choices. We would argue that a failure to acknowledge the multi-scalar nature of geographical context could result in a mismeasurement of neighborhood influence on individual level outcomes.

Taking advantage of the availability of individual level data with geo-coordinates we construct aggregates for individualized neighborhoods with different population counts. This approach to contextual measurement has previously been used by Bolster et al., (2007); Chaix et al., (2005); Macallister et al., (2001) and similarly in Andersson and Malmberg (2015). In our case we used the Equipop software developed by John Östh 
(Östh et al., 2014) to obtain aggregate information for neighborhoods that vary in scale; their size being measured by the population count, $k$. In order to handle the complexity that results from combining multiple scales with multiple indicators, we will take advantage of the possibilities offered by a factor analysis. By applying factor analysis to the multi-scalar measures of neighborhood composition, it becomes possible to identify the different types of neighborhood context discussed above.

Also, our selection of outcome variables is based on the idea of different links between neighborhood milieus and specific adult outcomes. Thus, we will use both poverty risks and indicators of early career success. The former will be measured based on incidence of high income. The latter is measured by social allowance recipiency and persistent low income.

We hypothesize that living at age 15 in elite areas will positively affect the income career as well as protect individuals from poverty in early adult life. A previous study has shown positive effects of elite areas on attainment of tertiary education (Andersson and Malmberg 2015) as have the results of earlier international research inspired by Bourdieu (1984), among others.

If growing up in neighborhoods with a high proportion of foreign-born residents exposes individuals to a higher proportion of newly arrived people and less helpful social networks, when it comes to finding well-paid work, one would expect this factor to be associated with poorer outcomes. Because we will construct a factor that is independent of contexts with high education and income, or high unemployment, any such effect should be independent of the socio-economic characteristics of the foreignborn. (R. Andersson, Musterd, Galster, \& Kauppinen, 2007)

Concentrations of social allowance in small-scale neighborhoods should also be associated with poorer outcomes concerning both income and social allowance in early adulthood (Mood, 2010). Neighborhoods are thus characterized by high proportions of non-employed and single mothers, which are traditionally associated with poorer outcomes in later life (Wilson, 1987).

Neighborhoods of 25,000 individuals or fewer, characterized by a high proportion of residents living in single-family housing, are hypothesized to be associated with higher educational attainment (E. K. Andersson \& Malmberg, 2015). Based on the same arguments as above, we might expect growing up in such neighborhoods to be associated with positive effects on income, and a reduced risk of receiving social allowances.

In order to measure how different neighborhood types affect early career success and poverty risk in adulthood we will use a cohort design based on longitudinal data that measures neighborhood exposure in adolescence (around age 15) and outcomes at the end of young adulthood (around age 30). If instead we had used cross-sectional data it is 
likely that correlations between individual income and neighborhood characteristics would have reflected the effects of income on where individuals live, not the other way around. Also, our design focuses on neighborhood effect mechanisms that operate during adolescence, which is considered an important formative period in an individual's life (Ainsworth, 2002).

However, the number of studies is relatively limited, especially studies using a long follow-up period (see e.g. Brännström, 2004; Oreopoulos, 2003). Moreover, most longitudinal studies focus on poverty outcomes and only a few consider individual income career. Lastly, some earlier studies have focused on particular metropolitan areas, which limits the variation in segregation for which contextual effects are measured (R. Andersson et al., 2007; Brännström, 2004). In comparison, studies that consider neighborhood effects on educational achievement are more numerous, possibly because such studies require a shorter follow-up period (E. Andersson \& Subramanian, 2006; E. K. Andersson \& Malmberg, 2015; Galster et al., 2007; Sykes, 2011).

Studies using a longitudinal design to analyze neighborhood effects on adult income from residential context in adolescence and childhood include Datcher (1982), Corcoran et al. (1992), Galster et al. (2007), Vartanian et al. (2005) and Islam (2013). The first two did not find significant neighborhood effects on adult income. Galster et al. (2007) found significant effects that were not robust when an instrument variable approach was used, whereas Islam (2013) found significant negative contextual effects on adult income from the neighborhood level poverty rates. All these studies used data from longitudinal studies (E. K. Andersson \& Malmberg, 2015) with relatively small sample sizes. In the Swedish context, Brännström's (2004) study is a prominent example.

Our study differs from the above studies in that we use a complete national sample based on register data and we employ a complete longitudinal design that relates adult outcome to neighborhood conditions during adolescence. In addition, it can be argued that our contextual measure is an improvement on earlier approaches (see Andersson and Malmberg 2015). We believe that this combination provides an opportunity to obtain more precise estimates of neighborhood effects on adult income and poverty risks than earlier studies.

\section{EMPIRICAL DESIGN, DATA AND METHODS}

The outcome variables in this study are indicators of poverty, low income, and high income at age 28-32 for a cohort born in 1980, and we will analyze the effect of neighborhood exposure at the age of 15 . Moreover, we will use contextual data from 1995, based on individualized neighborhoods ranging in scale from populations including the 12 nearest neighbors to areas including the 25,600 nearest neighbors for Sweden. However, in the contextual effect estimations we will not use statistical aggregates obtained for individualized neighborhoods directly. Instead, we will use factor scores resulting from a factor analysis carried out on the individualized- 
neighborhood-based data. We used ten factors, which we named according to their characteristics, as presented below. Since the outcome variables are categorical, a logit model will be used in order to assess the impact of individual level and contextual level variables.

\section{INDIVIDUAL LEVEL, COHORT AND HOUSEHOLD DATA}

The dependent variable social allowance is a dummy variable with a value of one if the individual had social allowance income in at least one year between 2008 and 2012 (see Table 1 below). Four different dummy variables based on the maximal disposable income for the individual in the period 2008 to 2012 were used to measure income career for the study population: Below $25^{\text {th }}$ percentile, Below $50^{\text {th }}$ percentile, Above 75 percentile and Above $90^{\text {th }}$ percentile. Percentiles were computed separately for each year and based on the study population. The coding based on the maximum percentile values implies that it is sufficient to have one year of income above the $75^{\text {th }}$ and $90^{\text {th }}$ percentile for the dummy variables Above 75 and Above $90^{\text {th }}$ to be coded as one. For the Below $25^{\text {th }}$ and Below $50^{\text {th }}$ dummies to be coded as one, on the other hand, it is necessary to have a disposable income below the $25^{\text {th }}$ and $50^{\text {th }}$ percentile for every year between 2008 and 2012. A motive for constructing the outcome variables as categorical is that low income and high income outcomes can be seen as a result of socialization processes that direct the life course of individuals towards specific paths.

As can be seen in Table 1, the proportions of men and women having a maximum value above the $75^{\text {th }}$ or $90^{\text {th }}$ percentile are strikingly different; therefore, we use separate models for men and women. This is also true when it comes to low (below $25^{\text {th }}$ and $50^{\text {th }}$ percentile) incomes for men and women.

To account for individual level influence on poverty and income career our statistical model includes eight indicators of parental background: parent(s) with social allowance, family type (single mother households and single father household), parent(s) with university education, not employed parent(s), parents' earned income in percentiles, parents' disposable income in percentiles, and Swedish-born parents (one or two). 'Not employed' is not the equivalent of being registered as unemployed at the national public agency for employment but instead means not having paid work in November and being registered as a taxpayer for an earned income, that is a person can be on parental leave, retired, travelling, a homemaker etc. as well as unemployed. The same variable is used below for the contextual measure. Descriptive statistics for these variables are given in Table 1. The data source is MONA (Microdata-ON-Line-Access) provided by Statistics Sweden.

Our final sample consists of 95,643 individuals. This can be compared to the 102,601 individuals born in 1980 that lived in Sweden in 1995. The main reason that the final sample is smaller is that 6046 of these individuals have missing information on the outcome variables. An additional 480 individuals have been excluded because we have 
not been able to match them with contextual data in 1995. Finally, 314 individuals have been excluded because they have missing data on parental background.

\section{CONTEXTUAL MEASUREMENT}

With respect to the use of individual background variables, the empirical design of this study is conventional. This is not the case, though, with our approach to context measurement. Here, instead, our study introduces two important approaches: first, and most importantly, we introduce contextual measures that are based on individually defined and scalable neighborhoods. Second, we introduce a factor analysis-based representation of the spatial variation in a socio-demographic context as a means to manage the wealth of information resulting from scalability and as a means to obtain orthogonal, clearly separated factors for our analysis.

\section{INDIVIDUALIZED AND SCALABLE NEIGHBORHOODS}

We measure neighborhood population compositions using individual centered neighborhoods based on population size. Thus, we have used register data containing information about individual residential location to compute contextual variables based on the population composition among an individual's nearest 12, 25, 50, 100, 200, 400, $800,1600,3200,6400,12800$, and 25600 neighbors for 1995 (for the population older than 25 years and the total population, depending on variables), see Table 2. (Östh et al., 2014)

Traditional measures of segregation such as the isolation index are strongly dependent on the size of the statistical units for which the segregation index has been computed. In the Equipop software, the individualized neighborhoods are obtained by expanding a circular buffer around each residential location until the population encircled by the buffer corresponds to the population threshold chosen. When this threshold is reached, the program computes aggregate statistics on a selected socio-economic variable for the encircled population. For example, we used the proportion of single mothers among the 100 closest neighbors. For the contextual measurements, we have used data from the PLACE ${ }^{1}$ database of Uppsala University. This body of data contains register-based, individual level data for the population in Sweden from 1990 to 2010 with geocodes of the residential location by 100 -meter squares. From this data, seven different sociodemographic indicators have been extracted and used as input for Equipop; see Table 2.

\footnotetext{
${ }^{1}$ PLACE, Population, Chorology and Employment Database
} 


\section{Factor Analysis, Contextual Variation}

With seven different characteristics and 12 different levels of neighborhood scale we obtain a total of 84 contextual indicators. These indicators should be seen as characteristics of a detailed location rather than as characteristics of a larger geographical subdivision.

We subjected the 84 contextual indicators to a principal components factor analysis, and varimax rotation. The best fitting model, as evidenced by proportional declines in eigenvalues and factor loadings above .40 was a seven-factor solution, capturing $67 \%$ of the original covariation. The seven factors demonstrate that both scale (number of neighbors) and substantive characteristics combine to describe the dimensions of an individual's neighborhood. The factors are orthogonal, thus clearly non-correlated for our further analysis. Moreover, the factors have been normalized to have zero means and a standard deviation of one.

Based on the factor loadings, we can characterize the seven dimensions (see Figure 1) as follows:

- Elite (factor 1): High proportions of people with tertiary education and disposable income above the $90^{\text {th }}$ percentile. Factor loadings range from .61 to .93 for education and .44 to .63 for income across neighborhood sizes, see Figure 1.

- Foreign-born (factor 2): High proportions of foreign-born for all neighborhood sizes (loadings range from .45 to .93); high proportions of unmarried mothers and social assistance recipients load marginally (.4 to .5) for the larger neighborhood sizes, see Figure 1.

- Small-scale non-employment (factor 3): High proportions of non-employed, low proportions for incomes above the 90th percentile for smaller-size neighborhoods.

- Large-scale non-employment (factor 4): High proportions of non-employed, low proportions for incomes above the 90th percentile for larger neighborhoods.

- Social allowance nearby (factor 5): High proportions of individuals receiving social assistance and high proportions of unmarried mothers in smaller neighborhoods.

- Single-family housing (factor 6): High proportions of persons living in singlefamily houses, across all neighborhood sizes (loadings range from .41 to .79). This factor is not only an urban-rural dimension; when mapped, even small towns include enough renters and apartment-dwellers to show lower scores for larger sizes of closest neighbors $(k>6400)$.

- Medium-scale non-employment (factor 7). High proportions of non-employed persons in neighborhoods of the medium range (400-1600), see Figure 1. (If this factor is excluded, factors 3 and 4 do not as clearly differentiate the small- and large-scale neighborhoods in terms of non-employment and income.) 
If these factors are compared to the different neighborhood types discussed in the introduction it can be seen that there is a clear correspondence. Factor 1 Elite can clearly be seen as capturing environments that can promote long education and advantageous careers. Factor 2 Foreign-born will pick up environments with many migrants. Factor 3, factor 4 , and factor 5 can be seen as related to poverty contexts and hence can be expected to increase the risk of poverty outcomes. Factor 5 Single-family housing can be interpreted as a measure of middle-class environments, and thus can be expected to promote longer education and increase the probability of high earnings. Instead the advantage of a multi-scalar approach demonstrated by these results is that multi-scalar measures of geographical context allow a separation of different types of neighborhood context that often cannot be reached if a single scale level is used (see Andersson and Malmberg, 2015). This separation of different dimensions in a neighborhood context using multi-scalar measures is made possible by variation in the correlations between indicator variables aggregated at different scale levels. If a single scale level is used, a similar separation is hindered by high levels of multi-collinearity.

\section{RESULTS}

\section{FAMILY BACKGROUND VARIABLES}

For the family background variables, the effects on risk of having social allowance, low disposable income and on having a high disposable income between age 28 and age 32 are very much as expected (see Table 3 ) and correspond well to the results in earlier studies referred to above both concerning social allowance and income variables (Brooks-Gunn \& Duncan, 1997; Mood, 2010).

- Individuals that at age 15 lived in households that received a social allowance have a strongly increased risk of receiving a social allowance themselves at least once between age 28 and 32. For men the odds ratio is 1.980 and for women 1.736 compared to individuals not having a background in such households, (model 1) in Table 3. Also the risk of having a disposable income below the $25^{\text {th }}$ and $50^{\text {th }}$ percentile is higher, models 2 and 3, Table 3 . The individuals from households with a social allowance also have a lower chance of receiving a high disposable income in the same age span, irrespective of whether high is defined as above the $75^{\text {th }}$ or $90^{\text {th }}$ percentiles.

- The same pattern is visible for individuals that at age 15 lived in single mother and single father households or in households where at least one parent was not employed. This increases this risk of receiving a social allowance between age 28 and 32 and decreases the chances of receiving a high disposable income (all estimates not significant) in the same age span, Table 3.

- Having at least one parent with tertiary education has the opposite effect. This radically reduces the risk of receiving a social allowance at age 28-32 and having a low disposable income. It also has a strong positive effect on the chances of 
receiving a high disposable income. The estimates in Table 3, moreover, indicate that the effects of parents' education are stronger for women than for men, and a statistical test (available from authors upon request) confirms that this is the case.

- The effect of household disposable income and earned income at age 15 is similar in direction to that of having at least one parent with tertiary education. It reduces the risk of receiving a social allowance and having a low income at age 28-32, and has a positive effect on the chances of receiving a high disposable income. Note that the effect stated in Table 3 shows the result of an increase in disposable and earned incomes from the $25^{\text {th }}$ to the $75^{\text {th }}$ percentile.

- Having Swedish-born parents is not a significant background variable for social allowance. However, Swedish-born parent(s) are significant for reducing the risk of having a low disposable income in adulthood.

\section{CONTEXTUAL LEVEL FACTORS}

The purpose of this study is to investigate how poverty risks and early income career at adult age are influenced by the different neighborhood contexts in early youth. The effects of the contextual factors that are reported in Table 3 are therefore of special interest in relation to this aim. Given that the values for the contextual factors have been normalized, the parameter estimates presented in Table 3 show the effect of an increase in the factor score by one standard deviation. Our first observation here is based on the chi-square values for the family background variables and the contextual level variables. The chi-square values are based on the differences in log likelihood that result from introducing the two sets of variables in addition to an intercept-only model. Thus, the values give an indication of how important each set of variables is for determining the outcome variables. Judging from the chi-square values it is clear that the family background variables in combination are more important than the contextual level variables, most clearly so for the risk of receiving social allowance between 28 and 32 years of age and for the risk of having a low income in the same age span. The chisquare values, however, also indicate that the contextual level variables are far from unimportant. This is a first indication that the approach to identifying contextual level effects that we have taken in this paper is fruitful.

A second observation is that the contextual level effects, judging from the chi-square values, appear to be stronger for more advantageous outcomes, disposable income above the 75th percentile and disposable income above the 90th percentile, than for poorer outcomes, social allowance and disposable income below the 25 th percentile, Table 3. This is also reflected in the significance levels of the estimated effects for contextual factors. For the $90^{\text {th }}$ percentile outcome, all the estimated effects are significant, whereas for social allowance and disposable income below the 25th percentile only about half of the estimates are significant. Looking at the sign of the point estimates, and ignoring significance levels, it is also clear that, in general, 
contextual factors that have a positive effect on advantageous outcomes have a negative effect on disadvantageous outcomes, see Table 3.

\section{CONTEXTUAL LEVEL EFFECTS ON DISPOSABLE INCOME}

The estimates for contextual level effects on both the high disposable incomes and low disposable incomes presented in Table 3 are to a large extent in line with what one might expect from theoretical discussions about how neighborhood context during adolescence can influence life course trajectories.

- Factor 1 Elite. Growing up in an elite neighborhood (that is, having high values on factor 1) does, in general, have a positive effect on an individual's chances of receiving a high income. The effect is stronger for women than for men. Our evaluation of the point estimates for women (in the range 1.20 to 1.26) is that these represent substantial effects for women that grow up in areas with high scores on the elite factor. From earlier studies it is known that elite contexts play a role in educational attainment. The stronger effect for women could result from education being more important for the income career for women than for men. For example, according to the estimates in model 5 of Table 3, women growing up in an area with an elite factor score of three would have a $100 \%$ increase in their odds of receiving a disposable income above the $90^{\text {th }}$ percentile relative to the baseline value of zero. This is stronger than the effect of having a parent with tertiary education (53\% increase). Given the level of socio-economic segregation in Sweden, there are few individuals that grow up in such high elite areas and, therefore, contextual level effects on most individuals will be weaker. However, this does not change the fact that the estimated statistical effect gives support to the idea that neighborhood context can strongly influence individual life course trajectories.

For women, coming from areas with a strong elite (factor 1) presence, on the other hand, gives some protection against the risk of low income. This can be seen as a mirror image of the positive effect of elite neighborhoods on the chances of getting a high income, but at the same time it is interesting to note the gender difference in the contextual effect. One interpretation of this finding is that an elite environment can strengthen the career orientation of young women and lessen their orientation towards a career that involves part-time work and, therefore, the risk of low income. A support for this interpretation is that having a parent with tertiary education also has a stronger protective effect against low income for women than for men.

- Factor 4 Large-scale non-employment. This is the contextual level factor that has the second largest effect on high income. The parameter estimates are in the range 0.89 to 0.93 (models 4 and 5, Table 3), indicating a decrease of around $10 \%$ in the odds of receiving a high income when the score for this factor increases by one 
unit, see Table 3. The same caveat as above concerning the number of individuals affected by effects of this size also applies here; that is, rather few individuals live in extreme areas.

- Factor 3 Small-scale non-employment and factor 5 Social allowance nearby. These contextual factors have similar effects on the odds of receiving a high income. The effects are in the range $4.6 \%$ to $7.7 \%$ lower odds for receiving a high income (see models 4 and 5, Table 3) but both have appreciably smaller overall effects than factors 1 and factor 4 . The gap in factor score values between the $10^{\text {th }}$ and $90^{\text {th }}$ percentile is about three for both factors, corresponding to a difference in effect that is of similar size to the combined effect of growing up in a household with a social allowance and an unemployed parent. However, for factor 5 there are a few locations that have very high scores, above 5 (97.5 percentile) (compare Mood, 2010). It could be of interest to investigate whether the effect of such high levels of exposure is linear, but this falls outside the scope of this paper.

With respect to the risk of experiencing low income in young adulthood, poor employment prospects in the area where individuals grew up stand out as important. The Large-scale non-employment factor (4) above is especially important for increasing the risk of low income, but small-scale non-employment (3) and factor 5 Social allowance nearby are also associated with risk increases.

- Factor 6 Single-family dwelling. For men, this factor has significant positive effects on the odds of receiving a high income, stronger for men than for women. The effects are relatively small (2\%-5\% range, models 4 and 5. Table 3). Also, living in single-family housing dominated areas is somewhat protective against low incomes in adult age, especially for men's disposable income below the $50^{\text {th }}$ percentile, model 2 in Table 3.

- Factor 2 Foreign-born. This factor has significant positive effects on the odds of receiving a high income in adult age for the 1980 cohort. The result is contrary to expectations in that growing up in a neighborhood dominated by migrants could have adverse effects on the prospects for a good income career. One reason could be that foreign-born composition as such has little effect when socio-economic composition is controlled for. Another possible reason is that our variable (foreignborn) is too broad to account for effects related to, for example, discrimination. However, the result is in line with the result in Andersson et al. (2007, p. 656) which did not find foreign-born neighborhood mix to be important to income; rather, the socio-economic mix of neighborhoods was important.

For women, factor 2 Foreign-born has a protective effect on the risk of receiving a low income.

- Factor 7 Medium-scale non-employment has no consistent significant effect on the odds of receiving a high or low income in young adulthood. 


\section{CONTEXTUAL LEVEL EFFECTS ON SOCIAL ALLOWANCE}

The estimated contextual effects on poor outcomes are, as pointed out above, in general inverse to the effects of advantageous outcomes, and less strong. For social allowance recipiency two contextual factors stand out as especially important: Social allowance nearby (factor 5) and Single-family housing (factor 6). The former increases the risk for social allowance recipiency and the latter decreases the risk. This is in line with the theoretical expectations and with earlier findings in the literature (Mood 2010). Growing up in areas with a concentration of poor households can affect expectations and opportunities negatively and, thus, increase the risk of poor adult outcomes. Here it can be noted that neighborhoods characterized by Social allowance nearby (factor 5) tend to increase the risk of having a low income, and this also supports the idea that a background in areas with a concentration of poor households can have negative effects on economic prospects. Conversely, the estimates for factor 6 single-family housing can be seen as suggesting that a background in neighborhoods dominated by owneroccupied single-family housing (factor 6) can foster attitudes and expectations that make individuals more capable of avoiding and addressing economic difficulties.

\section{CONTEXTUAL EFFECTS AND THE LEVEL OF SEGREGATION}

The extent to which adult outcomes vary between different neighborhoods will be determined by the level of segregation, as shown by the estimates of contextual factors in Table 3. High levels of segregation imply high variation in factor scores (Manley, Johnston, Jones, \& Owen, 2015) and, thus, large differences in expected outcome across neighborhoods. Examples of variation in scores between neighborhoods for factor 1 Elite, and factor 4 Large-scale non-employment scores in different commuting regions in Sweden are given in Figure 2.

Thus, the Munkfors labor market region (first row, Figure 2) is an example of a region with low segregation and thus low variation in factor scores. The upper left graph shows the low variation in the Elite factor, and there are almost no positive scores for the Elite factor in Munkfors. There is also low variation for the Large-scale non-employment factor but the scores are positive, indicating fairly high non-employment in the region (upper right graph).

The next example is Trollhättan, a region with moderate levels of segregation. Compared to Munkfors, Trollhättan has a wider variation of values for both factors (see graphs in the second row of Figure 2). This higher variation implies that at the extreme ends of the distribution there will be some contextual effects on the income careers for young adults, more so than in Munkfors. In Munkfors the effects of location on income career will be negligible. 
Even wider variation in factor scores and, thus greater differences between neighborhoods, is found in the Jönköping labor market region. The presence of a university college, and the larger city size are possible explanations for the positive incline of the Jönköping curves (row three, Figure 2). The increase in the factor 1 Elite, from about the $90^{\text {th }}$ percentile is evidence of neighborhoods with high elite representation, which in turn lead to larger effects on income careers.

The last example is the labor market region of Malmö (bottom row, Figure 2) a metropolitan area in the Swedish context (about 1 million inhabitants). In this region we find high levels of variation in factor scores across neighborhoods. The Malmö labor market region includes both Lund, a university town with a long academic tradition, and areas with manufacturing industries employing comparably unskilled labor. Large variation in factor scores across neighborhoods implies that location will strongly affect the income careers of individuals who grow up in the Malmö region.

In conclusion, this means that apart from family background effects on adolescents' future poverty and income careers, the segregation in regions and cities helps to form the life course trajectories of Swedish youths, and that these differences are greater in some regions than others, as shown by the region examples above.

\section{CONCLUDING DISCUSSION}

In this paper we have applied a new approach to contextual measurement in order to assess the effect of different neighborhood characteristics on early adult income career and poverty outcomes. In our theoretical framework we hypothesized that it would be possible to identify different dimensions in neighborhood context that could influence such outcomes. The empirical results that we have presented above largely support this idea.

There are positive contextual effects on early adulthood high income from adolescent residential areas with elite characteristics, and there are negative effects on high future incomes from poverty and non-employment contexts. Also, single-family housing contexts promote high incomes and protect from having social allowance in early adulthood. An exception to the expected results, but not unknown from earlier research, is the positive effects on high incomes of growing up in contexts characterized by foreign-born resident. This last result, as well as the other results, is found when at the same time controlling for individual/parental socio-demographic background.

In the literature, effects of neighborhood context on individual level income have been assessed as either weak or close to non-existent (Bolster et al., 2007; Van Ham, Manley, Bailey, Simpson, \& Maclennan, 2012). Our results agree with earlier studies that for most individuals, variation in neighborhood context has little impact on their income career. However, if effect sizes are computed not for individuals that grow up in average neighborhoods but for individuals from the most advantaged or most disadvantaged 
neighborhoods, the contextual level impact turns out to be comparable with the effects of important elements of family background such as parental income, parental education or social allowance recipiency. These relatively strong effects of residential context are found for the probability of having a high income around age 30 but not to the same extent for the risk of receiving social allowance and having low income. From this we draw four tentative conclusions.

Firstly, the Swedish welfare state used to be effective in protecting individuals from poverty, as measured by social allowances. When the contextual effects on poverty are compared to those found in an earlier longitudinal study by Brännström (2005) on individuals born in the 1950s, where no effects on either poverty or social allowance were found, we do find stronger effects. One reason could be that the mid-1990s was a period of economic crisis and welfare state retrenchment. When poverty was measured by low incomes we found large-scale non-employment areas increased the risk of the 1980 cohort having below the $25^{\text {th }}$ and $50^{\text {th }}$ percentiles of disposable income in adult age.

Secondly, segregation levels have increased with time, especially in the metropolitan areas, partly because of a greater diversity in the total Swedish population resulting from a larger inflow of international migrants. Therefore, the 1980 cohort that we studied had been exposed to higher levels of segregation compared to the cohort studied by Brännström (2005).

Thirdly, and in accordance with Chetty et al. (2014), neighborhood effects in combination with high levels of segregation pose a risk of impeding social mobility. From the results of strong effects (negative and positive) on income careers in areas deviating from factor means in labor market regions we can conclude that there is a risk that intergenerational income mobility is also hindered in Sweden.

Moreover, that the estimated contextual effects are important implies that parents who make residential choices on the basis of ideas about how different neighborhoods might influence their children's future are not necessarily mistaken. In this study we found that the factor of single-family housing did have a protective effect against social allowance for adolescents growing up in such areas. To reside in single-family housing areas is thus to be socialized into adopting behaviors and developing capacities that promote finding a job and earning an income to support oneself. Of course, it could be argued that such parental choice, if linked to unobserved characteristics of the families that influence children's life courses, can imply that estimated contextual effects are not truly causal.

Fourthly, in earlier studies of neighborhood effects in Sweden (R. Andersson et al., 2007; Brännström, 2005) there are suggested policy implications to consider. When no neighborhood effects are found, strong arguments for mixing policies are lacking, and general welfare policies can be seen as more effective than area-based policies. Our results, on the other hand, point in the opposite direction. Both area-based policies and 
mixing can be seen as important for hindering the effects on adolescents of growing up in disadvantaged areas. Area-based programs are important for creating equal opportunities, and mixing policies are important for preventing strict sorting and strong residential segregation.

Moreover, we conclude that the empirical design of this paper, which combines a longitudinal design, the use of a large, register-based sample, and measures of context based on individualized, scalable neighborhoods with a combination of indicators, has resulted in more precise estimates than earlier studies. We believe that our improved contextual measure is one reason why we find comparatively strong neighborhood effects. Another possible explanation for why we find neighborhood effects is that the use of a national sample that includes individuals from regions with low levels of segregation may have increased the variation in residential context among individuals with similar parental background. Moreover, the longitudinal design is important since children and adolescents are considered to be extra susceptible to the social and physical surroundings. The result of this study is an image of two strands. Individuals coming from affluent and less affluent residential areas in Sweden are already under strong influence of differences in family background. But because of contextual influences between living in the least advantaged areas and the most advantaged areas, there is a risk that high levels of segregation will induce individuals with different backgrounds to drift even further apart.

\section{Funding}

Stockholm University Linnaeus Center on Social Policy and Family Dynamics in Europe, SPaDE, the Swedish Research Council. $349-2007-8701$ 


\section{REFERENCES}

Ainsworth, J. W. (2002). Why does it take a Village? The Mediation of Neighborhood Effects on Educational Achievement. Social Forces, 81(1), 117-152.

Andersson, E., \& Subramanian, S. V. (2006). Explorations of neighborhood and educational outcomes for young Swedes. Urban Studies, 43(11), 2013-2025.

Andersson, E. K., \& Malmberg, B. (2015). Contextual effects on educational attainment in individualised, scalable neighbourhoods: Differences across gender and social class. Urban Studies, 52(12), 2117-2133. doi:10.1177/0042098014542487

Andersson, R., Musterd, S., Galster, G., \& Kauppinen, T. M. (2007). What Mix Matters? Exploring the Relationships between Individuals' Incomes and Different Measures of their Neighbourhood Context. Housing Studies, 22(5), 637-660. doi:10.1080/02673030701474602

Barthon, C., \& Monfroy, B. (2010). Sociospatial Schooling Practices: A Spatial Capital Approach. Educational Research and Evaluation, 16(2), 177-196.

Bolster, A., Burgess, S., Johnston, R., Jones, K., Propper, C., \& Sarker, R. (2007). Neighbourhoods, households and income dynamics: a semi-parametric investigation of neighbourhood effects. Journal of Economic Geography, 7(1), 1-38.

Bourdieu, P. (1984). Distinction: A social critique of the judgement of taste (R. Nice, Trans.): Cambridge, MA: Harvard University Press.

Brooks-Gunn, J., \& Duncan, G. J. (1997). The Effects of Poverty on Children. The Future of Children, 7(2), 55-71. doi:10.2307/1602387

Brännström, L. (2004). Poor Places, Poor Prospects? Counterfactual Models of Neighbourhood Effects on Social Exclusion in Stockholm, Sweden. Urban Studies, 41(13), 2515-2537. doi:10.1080/0042098042000294547

Brännström, L. (2005). Does neighbourhood origin matter? A longitudinal multilevel assessment of neighbourhood effects on income and receipt of social assistance in a Stockholm birth cohort. Housing, Theory and Society, 22(4), 169-195.

Chaix, B., Merlo, J., Subramanian, S. V., Lynch, J., \& Chauvin, P. (2005). Comparison of a Spatial Perspective with the Multilevel Analytical Approach in Neighborhood Studies: The Case of Mental and Behavioral Disorders due to Psychoactive Substance Use in Malmö, Sweden, 2001. American Journal of Epidemiology, 162(2), 171-182. doi:10.1093/aje/kwi175

Chetty, R., Hendren, N., Kline, P., \& Saez, E. (2014). Where is the land of opportunity? the geography of intergenerational mobility in the united states. Retrieved from

Clark, W. A., Anderson, E., Östh, J., \& Malmberg, B. (2015). A Multiscalar Analysis of Neighborhood Composition in Los Angeles, 2000-2010: A Location-Based Approach to Segregation and Diversity. Annals of the Association of American Geographers, 105(6), 1260-1284.

Corcoran, M., Gordon, R., Laren, D., \& Solon, G. (1992). The association between men's economic status and their family and community origins. Journal of Human Resources, 575-601.

Datcher, L. (1982). Effects of community and family background on achievement. The review of Economics and Statistics, 32-41.

Doling, J., \& Ronald, R. (2010). Property-based welfare and European homeowners: how would housing perform as a pension? Journal of Housing and the Built Environment, 25(2), 227-241. doi:10.1007/s10901-010-9184-7

Friedrichs, J. (1998). Do poor neighborhoods make their residents poorer? Context effects of poverty neigborhoods on residents. In H.-J. Andress (Ed.), Empirical Poverty Reseach in a Comperative Perspective (pp. 77-99). Aldershot, Brookfield USA, Singapore, Sydney: Ashgate.

Friedrichs, J. (2015). Neighbourhood effects: lost in transition?. Paper presented at the ENHR Conference, Lisbon, June 28 - July 1, 2015, Working Group "Poverty Neighbourhoods", Lisbon.

Galster, G., Marcotte, D. E., Mandell, M., Wolman, H., \& Augustine, N. (2007). The influence of neighborhood poverty during childhood on fertility, education, and earnings outcomes. Housing Studies, 22(5), 723-751.

Holloway, S. R., \& Mulherin, S. (2004). The effect of adolescent neighborhood poverty on adult employment. Journal of Urban Affairs, 26(4), 427-454.

Holloway, S. R., Wright, R., \& Ellis, M. (2012). The racially fragmented city? Neighborhood racial segregation and diversity jointly considered. The Professional Geographer, 64(1), 63-82. 
Islam, T. (2013). Childhood neighborhood conditions and the persistence of adult income. Regional Science and Urban Economics, 43(4), 684-693.

Jencks, C., \& Mayer, S. E. (1990). The social consequences of growing up in a poor neighborhood. In L. E. Lynn \& M. F. H. McGeary (Eds.), Inner-city poverty in the United States (pp. 111-186). Washington DC: National Academy Press.

Ludwig, J. (1999). Information and inner city educational attainment. Economics of Educational Review, 18(1), 17-30.

Macallister, I., Johnston, R. J., Pattie, C. J., Tunstall, H., Dorling, D. F. L., \& Rossiter, D. J. (2001). Class Dealignment and the Neighbourhood Effect: Miller Revisited. British Journal of Political Science, 31(01), 41-59. doi:doi:10.1017/S0007123401000035

Manley, D., Johnston, R., Jones, K., \& Owen, D. (2015). Macro-, Meso- and Microscale Segregation: Modeling Changing Ethnic Residential Patterns in Auckland, New Zealand, 2001-2013. Annals of the Association of American Geographers, 105(5), 951-967. doi:10.1080/00045608.2015.1066739

Massey, D. S., Gross, A. B., \& Shibuya, K. (1994). Migration, Segregation, and the Geographic Concentration of Poverty. American sociological review, 59(3), 425-445.

McCulloch, A. (2001). Teenage childbearing in Great Britain and the spatial concentration of poverty households. Journal of epidemiology and community health, 55(1), 16-23.

Mood, C. (2010). Neighborhood Social Influence and Welfare Receipt in Sweden: A Panel Data Analysis. Social Forces, 88(3), 1331-1356. doi:10.1353/sof.0.0304

Oreopoulos, P. (2003). THE LONG-RUN CONSEQUENCES OF LIVING IN A POOR NEIGHBORHOOD. Quarterly Journal of Economics, 118(4), 1533-1575. doi:10.1162/003355303322552865

Reardon, S. F., Farrell, C. R., Matthews, S. A., O'Sullivan, D., Bischoff, K., \& Firebaugh, G. (2009). Race and space in the 1990s: Changes in the geographic scale of racial residential segregation, 19902000. Social Science Research, 38(1), 55-70.

South, S. J., \& Crowder, K. D. (1999). Neighborhood effects on family formation: Concentrated poverty and beyond. American sociological review, 113-132.

Sykes, B. (2011). Spatial order and social position: Neighbourhoods, schools and educational inequality. (PhD), University of Amsterdam, Amsterdam. Retrieved from http://dare.uva.nl/record/365250

Toft, M. (2015). High-class living: Truly affluent neighbourhoods in Norway. Paper presented at the European Network for Housing Research Conference 2015, Lisbon June 29 - July 1.

van Ham, M., \& Manley, D. (2009). The effect of neighbourhood housing tenure mix on labour market outcomes: a longitudinal investigation of neighbourhood effects. J Econ Geogr, Ibp017. doi:10.1093/jeg/lbp017

Van Ham, M., Manley, D., Bailey, N., Simpson, L., \& Maclennan, D. (2012). Neighbourhood effects research: new perspectives: Springer.

Vartanian, Thomas P., \& Buck, Page W. (2005). Childhood and Adolescent Neighborhood Effects on Adult Income: Using Siblings to Examine Differences in Ordinary Least Squares and Fixed Effect Models, 60.

Wacquant, L. (2008). Urban Outcasts A Comparative Sociology of Advanced Marginality. Cambridge: Polity Press.

Wilson, W. J. (1987). The Truly Disadvantaged: The Inner City, the Underclass, and Public Policy. Chicago and London: The University of Chicago Press.

Östh, J., Malmberg, B., \& Andersson, E. (2014). Analysing segregation with individualized neighbourhoods defined by population size. In C. D. Lloyd, I. Shuttleworth, \& D. Wong (Eds.), Social-Spatial Segregation: Concepts, Processes and Outcomes (pp. 135-161): Policy Press. 
TABLE 1 DESCRIPTIVE STATISTICS, OUTCOME VARIABLES 2008-2012 AND INDIVIDUAL BACKGROUND VARIABLES IN 1995.

TABLE 2. VARIABLES USED WITH EQUIPOP TO MEASURE RESIDENTIAL CONTEXT IN 1995.

TABLE 3. PARAMETER ESTIMATES, EXP(ß), FOR FIVE MODELS FOR POVERTY AND INCOME VARIABLES, 1995.

FIGURE 1. FACTOR LOADINGS AT DIFFERENT SCALES. LOADINGS ON THE Y-AXIS AND $K$ NUMBER OF CLOSEST NEIGHBORS ON X-AXIS. (TO REDUCE CLUTTER, THESE GRAPHS ONLY SHOW FACTORS THAT FOR AT LEAST ONE K-LEVEL HAVE A LOADING HIGHER THAN 0.2 OR LOWER THAN -0.2.)

FIGURE 2. PERCENTILES OF FACTOR 1 ELITE AND FACTOR 4 LARGE-SCALE NON-EMPLOYMENT IN THE LABOR MARKET REGIONS OF MUNKFORS, TROLLHÄTTAN, JÖNKÖPING AND MALMÖ. 
TABLE 1 DESCRIPTIVE STATISTICS, OUTCOME VARIABLES (BASED ON 2008-2012 DATA) AND INDIVIDUAL BACKGROUND VARIABLES (1995 DATA).

\begin{tabular}{|c|c|c|c|c|c|c|}
\hline $\begin{array}{l}\text { At least one year from } 2008 \text { to } 2012 \\
\text { with: }\end{array}$ & $\mathbf{N}$ & Proportion & Women & $\begin{array}{c}\text { Women } \\
\text { Proportion }\end{array}$ & Total & $\begin{array}{c}\text { Over all } \\
\text { proportion }\end{array}$ \\
\hline At least one year with social allowance & 49123 & .08 & 46520 & .07 & 95643 & .07 \\
\hline $\begin{array}{l}\text { Maximum disposable income below } 25^{\text {th }} \\
\text { percentile (all years) }\end{array}$ & 49123 & .04 & 46520 & .09 & 95643 & .07 \\
\hline $\begin{array}{l}\text { Maximum disposable below } 50^{\text {th }} \\
\text { percentile (all years) }\end{array}$ & 49123 & .18 & 46520 & .36 & 95643 & .27 \\
\hline $\begin{array}{l}\text { Maximum disposable income above } 75^{\text {th }} \\
\text { percentile }\end{array}$ & 49123 & .57 & 46520 & .36 & 95643 & .47 \\
\hline $\begin{array}{l}\text { Maximum disposable income above } 90^{\text {th }} \\
\text { percentile }\end{array}$ & 49123 & .31 & 46520 & .16 & 95643 & .24 \\
\hline Parent social allowance & & & & & 95643 & .11 \\
\hline Earned income percentile & & & & & 95643 & 60.84 \\
\hline Disposable income percentile & & & & & 95643 & 50.39 \\
\hline Parent university education & & & & & 95643 & .38 \\
\hline Parent not employed & & & & & 95643 & .24 \\
\hline Single mother household & & & & & 95643 & .19 \\
\hline Single father household & & & & & 95643 & .04 \\
\hline Swedish born parent & & & & & 95643 & .88 \\
\hline
\end{tabular}

TABLE 2. VARIABLES USED WITH EQUIPOP TO MEASURE RESIDENTIAL CONTEXT IN 1995.

\begin{tabular}{|c|c|c|c|}
\hline Variable & Description & Population & Number of neighbors $(k)$ \\
\hline Education & $\begin{array}{l}1=\text { university/college, } 0=\text { not } \\
\text { university/college }\end{array}$ & $>25$ years & $\begin{array}{l}12,25,50,100,200,400, \\
800,1600,3200,6400, \\
12800,25600\end{array}$ \\
\hline Social allowance & $\begin{array}{l}1=\text { social allowance, } 0=\text { not } \\
\text { social allowance }\end{array}$ & All & (same as above) \\
\hline Family type & $\begin{array}{l}1=\text { single mother }, 0=\text { not single } \\
\text { mother }\end{array}$ & $>25$ years & (same as above) \\
\hline Disposable income & $\begin{array}{l}\text { Disposable income, average } \\
\text { percentile }\end{array}$ & $>25$ years & (same as above) \\
\hline Foreign-born & $\begin{array}{l}1=\text { foreign-born, } 0=\text { born in } \\
\text { Sweden }\end{array}$ & All & (same as above) \\
\hline Non-employed & $\begin{array}{l}1=\text { non-employed, } 0= \\
\text { employed }\end{array}$ & $>25$ years & (same as above) \\
\hline Housing (1996) & $\begin{array}{l}1 \text { = Single family housing, } 0= \\
\text { other types of housing }\end{array}$ & All & \\
\hline
\end{tabular}


TABLE 3. PARAMETER ESTIMATES, EXP( $\beta)$, FOR FIVE MODELS FOR POVERTY AND INCOME VARIABLES, 1995.

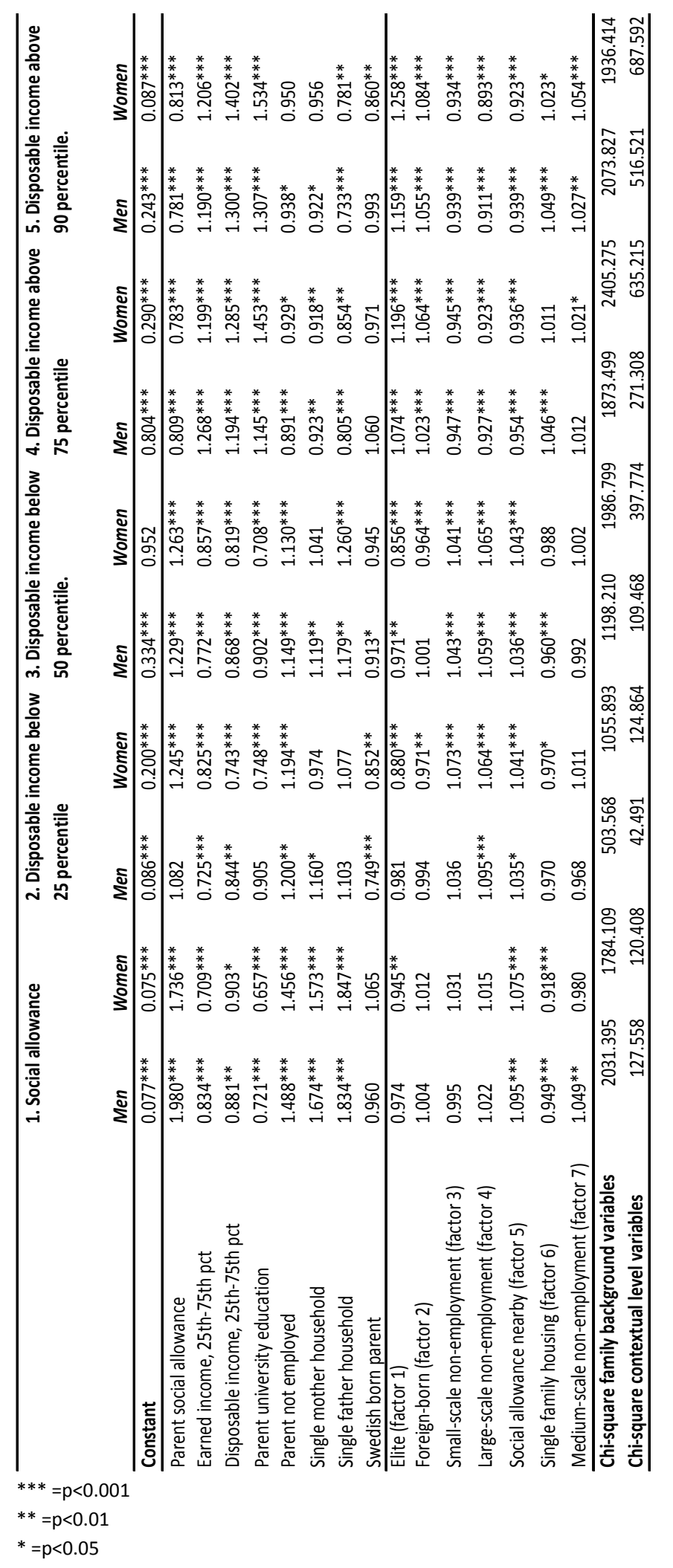



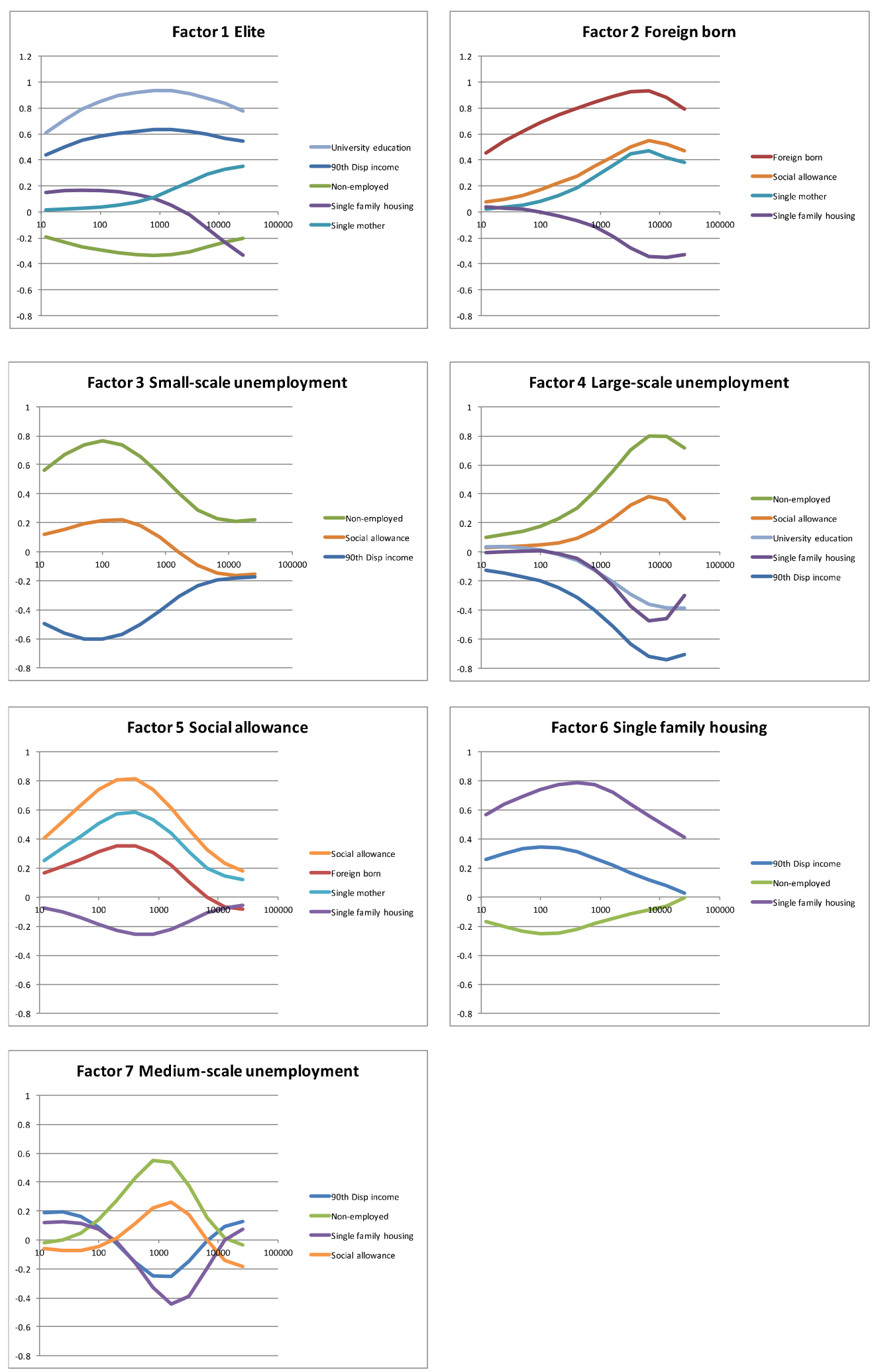

FIGURE 1. FACTORLOADINGS AND SCALE. FACTOR LOADINGS ON THE Y-AXIS AND $K$ NUMBER OF CLOSEST NEIGHBORS ON X-AXIS. (TO REDUCE CLUTTER, THESE GRAPHS ONLY SHOW FACTORS THAT FOR AT LEAST ONE $K$ LEVEL HAVE A LOADING HIGHER THAN 0.2 OR LOWER THAN -0.2.) 


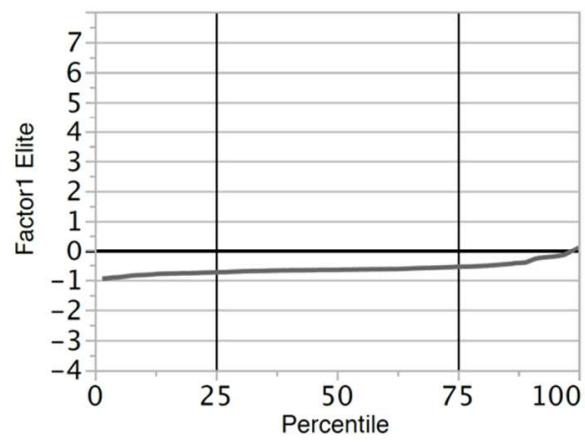

Plot for Namn=Munkfors

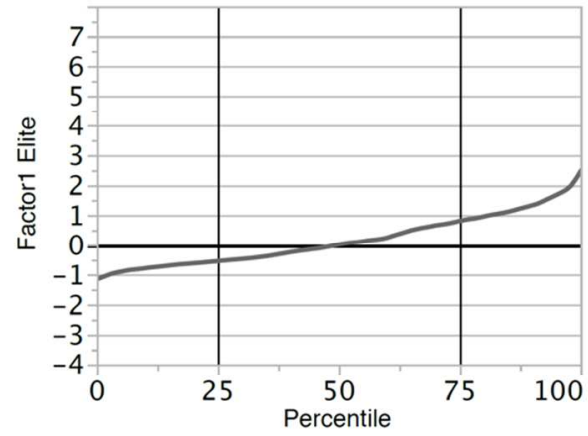

Plot for Namn=Trollhättan

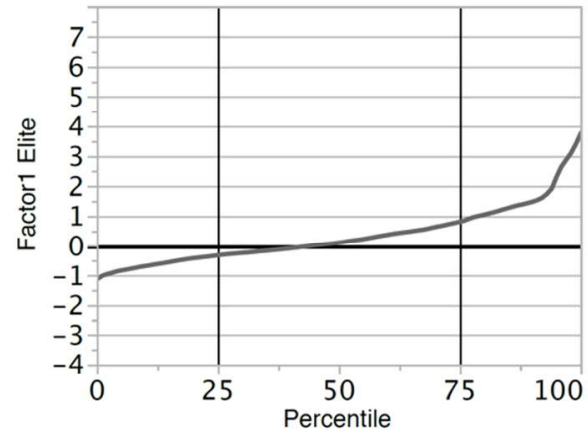

Plot for Namn=Jönköping

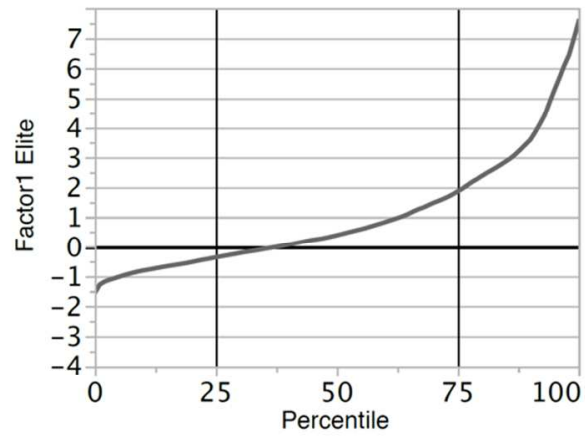

Plot for Namn=Malmö

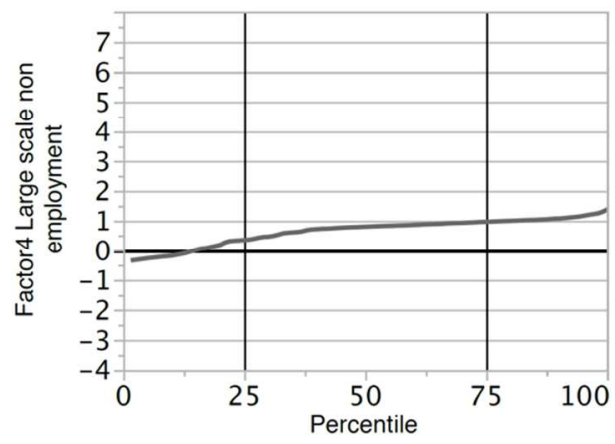

Plot for Namn=Munkfors

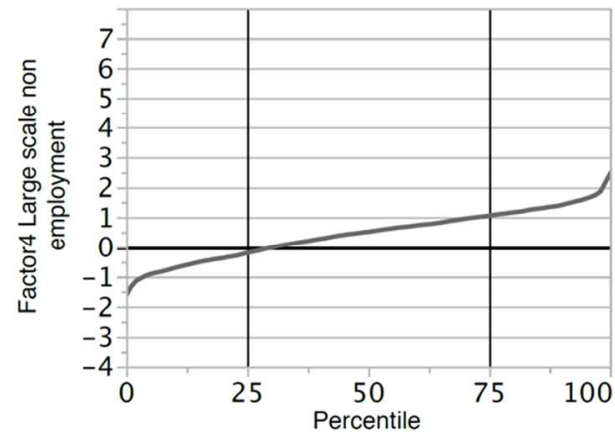

Plot for Namn=Trollhättan

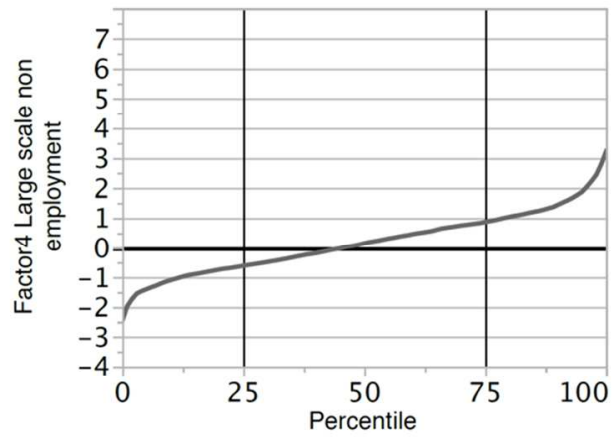

Plot for Namn=Jönköping

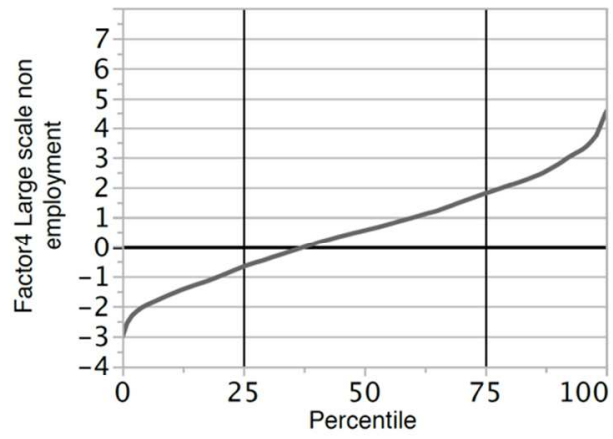

Plot for Namn=Malmö

FIGURE 2. PERCENTILES OF FACTOR 1 ELITE AND FACTOR 4 LARGE SCALE NON EMPLOYMENT IN THE LABOR MARKET REGIONS OF MUNKFORS, TROLLHÄTTAN, JÖNKÖPING AND MALMÖ. 